\title{
THE ROLE OF DIFFUSION TENSOR IMAGING (DTI) IN SPINAL CORD PATHOLOGY
}

\author{
Hend Galal Eldeen Mohamed Ali Hassan *, Rania Ali Maarouf*, Mohamed \\ Amr Farouk Abo-Elela** and Norhan Ramzy Mohamady***
}

\author{
*Department of Radiodiagnosis, \\ Faculty of medicine, Ain Shams \\ University. \\ ** Department of Radio- \\ diagnosis, Air force hospital \\ *** Department of Radio \\ diagnosis, Elsheikh Zayed Al- \\ Nahian hospital. \\ Cairo , Egypt \\ Corresponding: \\ Norhan Ramzy Mohamady \\ Mobile : 01067444521 \\ Email: \\ dr.nonna_2009@yahoo.com \\ Received: $12 / 2 / 2020$ \\ Accepted: 4/3/2020
}

Online ISSN: $2735-3540$

\begin{abstract}
:
Background: Many patients complain from sensory deficient secondary to different causes, although the magnetic resonance (MR) shows the mass effect or changes of spinal cord yet it is still limited in predicting symptoms everity as patients may have a varying tolerance of spinal cord compression. Diffusion tensor imaging (DTI) shows could predict degree of spinal cord affection even with mild lesions.
\end{abstract}

Aim of the work: is to show the role of Diffusion tensor imaging(DTI) in proved different cervical or dorsal spinal lesions by conventional MRI.

Patients and Method: The study included 16 patients divided into 6 patients complaining from compressive disc lesions with sensory deficient,2 patients with neoplasm complain from newly developed sensory deficient patients with and 8 patients complaining from internal spinal cord lesions in the form of single spinal multiple sclerosis (MS) plaque. All cases are considered as self control by measuring two controls above and below lesion.

Results: High statistically significant difference of fractional anisotropy (FA) between lesion and control with statistically significant difference of apparent diffusion coefficient (ADC) between lesion and control (Mann-Whiteny Test $p$ value $<0.05$ ), resultant cut off value is 0.333 which gives higher specificity and sensitivity with efficacy $87.5 \%$.

Conclusion: the resulted values of newly designed protocol give functional and numerical marker by which the diagnosis and prognosis will be more suitable.

Keywords: Spinal cord, DTI, FA and ADC.

\section{INTRODUCTION:}

Myelopathy describes any neurologic deficit related to the spinal cord which usually occurs due to compression of the spinal cord by osteophyte or extruded disc material in the cervical and dorsal spine. Other common sources of myelopathy are cord compression due to extra-dural mass caused by carcinoma metastasis to bone and trauma. Many primary neoplastic tumors, infectious, inflammatory, neurodegenerative, vascular, nutritional, and idiopathic disorders result in myelopathy ${ }^{[1]}$.

Magnetic resonance imaging (MRI) is currently by far the most important imaging modality of the central nervous system (CNS). It provides excellent anatomical information about the spinal cord macrostructure ${ }^{[2,3]}$.

The magnetic resonance (MR) shows the mass effect on the spinal cord which may be associated with abnormal signal intensity 
on T2-weighted imaging sequence yet it is still limited in predicting symptom severity as patients may have a varying tolerance of spinal cord compression. The T2W changes are often a late finding and may predict worse outcome despite decompression ${ }^{[4,5]}$.

The diffusion tensor imaging (DTI) is an advanced non-invasive technique of magnetic resonance (MR) which enables visualization of the white matter tracts and assessment of their integrity not only through qualitative way but also in quantitative way by utilizing the diffusion of water molecules to act as a probe for assessing tissue microstructure ${ }^{[6,7]}$.

The diffusion tensor imaging (DTI) results are quantified by two primary parameters: the apparent diffusion coefficient (ADC) value which refers to the overall diffusivity of the tissue irrespective of directional dependence, and the fractional anisotropy (FA) value which reflects the directional dependence of the diffusion process and is expressed as a relative number ranging from 0 to 1 that increases in relation to the anisotropic diffusion within the tissue being evaluated ${ }^{[8]}$.

In the spinal cord compression the diffusion tensor imaging (DTI) and tractography patterns shows the intact versus disrupted fiber bundles and although it is not associated with the severity of symptoms ${ }^{[9,10]}$.

\section{PATIENT AND METHODS:}

It is a retrospective case control study included 16 patients ( 6 females and 10 male patients) complaining from numbness of the upper limbs. All patients underwent conventional cervical or dorsal MRI study as first investigation tool then MRI with diffusion tensor imaging sequence in patients with positive findings. Inclusion criteria involving patients with positive finding in conventional cervical MRI.
Exclusion criteria any patients with contra-indication for MRI, e.g. an implanted magnetized device, pacemaker and claustrophobia, Patients with cervical or dorsal vertebral bodies fixation by screws.

- MR diffusion tensor imaging technique

Images were obtained using closed 1.5 Tesla MR System Acheiva Philips Magnet and phased array coil. Patient was in supine position with the head first. Different MRI sequences were obtained included sagittal T1 (TR $800 \mathrm{~ms}$, TE 7.8), sagittal T2 (TR 2680, TE 100), axial FEE (TR 500, TE 9) and axial DTI (TR 7100, TE 70). Sagittal STIR sequence (TR 3500, TE 80) was done in patients with MS. Post processing acquisition of the resulted DTI imaging using Philips software for tractography (Philips extended MR workspace), by drawing similar region area of interest (ROI) size at area of lesion, areas above and below (control 1 and 2 respectively).

\section{RESULTS:}

The study included 16 patients, 8 patients with MS, 6 patients with disc lesions and 2 patients with bone metastasis.

The results between all lesions and control 1 showed highly significant FA value with mean of $(0.35 \pm 0.131 \mathrm{SD})$, (Mann- Whiteny test $p=0.001$ ), and significant ADC value with mean of (1.061 \pm 0.454 SD) (Mann- Whiteny test $p=$ 0.031), while the results between all lesions and control 2 showed highly significant FA value with mean of $(0.35 \pm 0.131$ SD)(Mann- Whiteny test $p=0.002)$, and significant ADC value with mean of (1.061 \pm 0.454 SD)(Mann- Whiteny test $p=0.02$ ).

The results also included FA cut off value of 0.333 between all lesions and control $(1+2)$ groups with sensitivity $62.5 \%$, specificity 100 ,-ve predictive value $84.2 \%,+$ ve predictive value $100 \%$ and accuracy $87.5 \%$. Cut off value of ADC was 
1.36 which had sensitivity $75 \%$, specificity predictive value $75 \%$ and accuracy $83.3 \%$. $87.5 \%$,-ve predictive value $87.5 \%,+$ ve

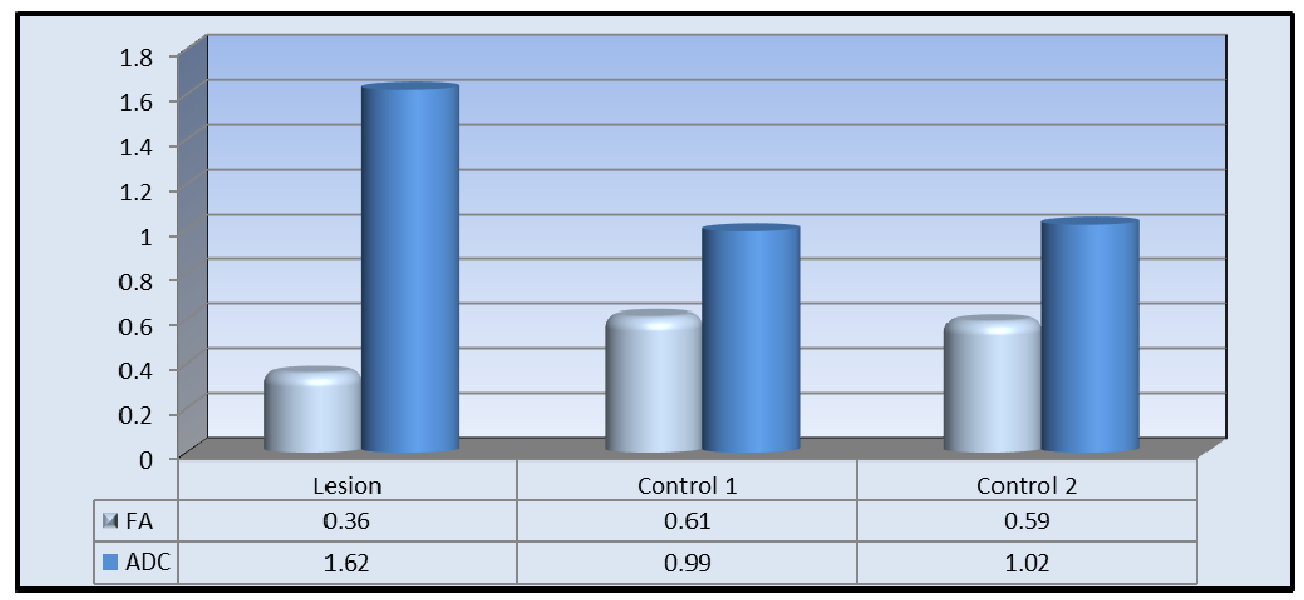

Chart 1: All lesions vs control 1+2

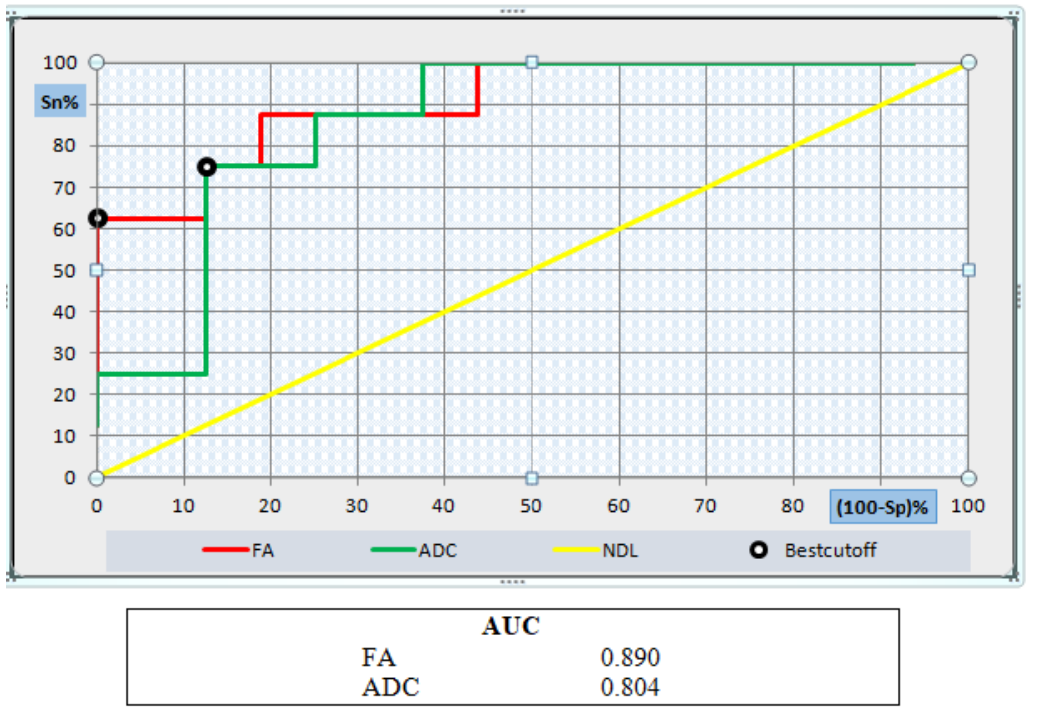

Fig. (1): ROC curve analysis showing the diagnostic performance of FA and ADC for discriminating patients with lesions (internal and compressive) from control $(1+2)$

The results between MS plaques lesions and control 1 showed significant FA value with mean of $(0.292 \pm 0.087$ SD)(MannWhiteny test $\mathrm{p}=0.029)$, and non significant ADC value with mean of $(1.79 \pm 0.53 \mathrm{SD})$ (Mann- Whiteny test $\mathrm{p}=0.218$ ), while the results between MS plaques lesions and control 2 showed significant FA value with mean of $(0.292 \pm 0.0 .087$ SD) (MannWhiteny test $p=0.011)$, non-significant
ADC value with mean of $(1.79 \pm 0.53 \mathrm{SD})$ (Mann- Whiteny test $\mathrm{p}=0.119$ ).

The results also included cut off value of FA $=0.333$ between MS lesions and control $(1+2)$ groups which had sensitivity $75 \%$, specificity $100 \%$,-ve predictive value $88.9 \%,+$ ve predictive value $100 \%$ and accuracy $91.7 \%$ and cut off value of ADC $=2.145$ which had sensitivity $50 \%$,specificity $100 \%$,-ve predictive value $80 \%$, +ve predictive value $100 \%$ and accuracy $83.3 \%$. 


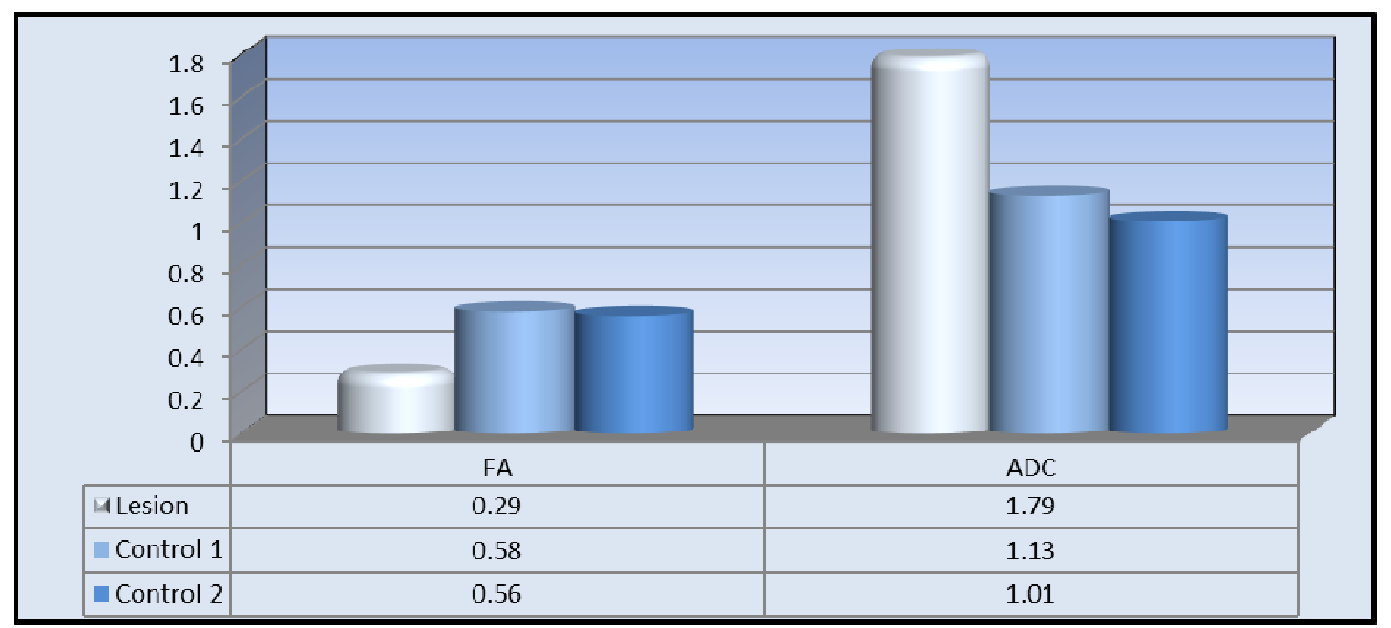

Chart 2: MS lesions vs control 1+2

The results between compressive (disc and metastatic) lesions and control 1 showed significant FA value with mean of $(0.42 \pm$ 0.147 SD) (Mann- Whiteny test $p=0.048$ ), and significant ADC value with mean of $(1.44 \pm 0.34$ SD)(Mann- Whiteny test $\mathrm{p}=$ $0.045)$, while the results between disc lesions and control 2 showed non-significant FA value with mean of $(0.421 \pm 0.147 \mathrm{SD})$ (Mann- Whiteny test $\mathrm{p}=0.08$ ), and non significant ADC value with mean of (144 \pm $0.34 \mathrm{SD}$ ) (Mann- Whiteny test $\mathrm{p}=0.099$ ).
The results also included cut off value of $\mathrm{FA}=0.316$ between compressive lesions and control $(1+2)$ groups which had sensitivity $50 \%$, specificity $100 \%$,-ve predictive value $80 \%$, +ve predictive value $100 \%$ and accuracy $83.3 \%$.Cut off value of $\mathrm{ADC}=1.36$ which had sensitivity $75 \%$, specificity $100 \%$,-ve predictive value $88.9 \%,+$ ve predictive value $100 \%$ and accuracy $91 \%$.

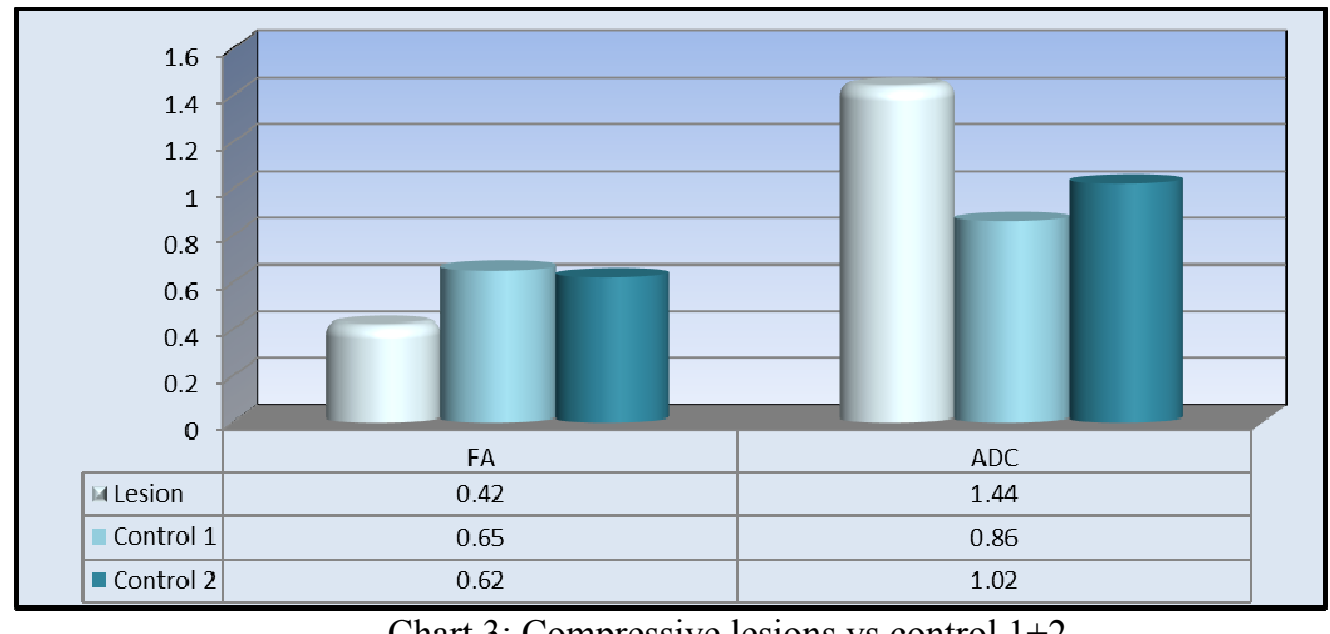

Chart 3: Compressive lesions vs control 1+2

\section{DISCUSSION:}

MS is an acquired chronic immunemediated inflammatory condition of the central nervous system, affecting both the brain and spinal cord ${ }^{[11]}$.

Cervical cord involvement is most frequent clinical site of involvement in 
spinal MS, our study showed FA value is affecting even with subtle change in T2 signal of the spinal cord which agree with studies showed decreasing degree of FA values in early-stage lesions is parallel to the clinical prognosis with lesser change being correlated with better prognosis ${ }^{[12,13]}$.

Our study resulted the more the decreased the FA value, the more neurological symptoms patients had, this is in agree with study reporting decrease in FA value reflects axonal injury, correlation with clinical recovery has been seen; the lower the FA values, the more severe is the injury (figure 2,3), with the more serious neurological dysfunction and the worse outcome ${ }^{[14]}$.

On the other hand, early remyelination could result in the reconstruction of fasciculus anisotropy, leading to an increase in FA values which implies a better prognosis $^{[15]}$. Furthermore, the decreasing of ADC values in acute lesions might be related to the proliferation of astrocytes and oligodendrocytes, which can represent remyelination and clinical recovery, also suggesting a more favorable outcome ${ }^{[16]}$, that represented in our study by increased FA and decreased ADC values in patient's have multiple plaques.

MRI is the modality of choice for assessing cervical spondylosis ${ }^{[17]}$;our study showed decrease FA and increase ADC in mild disc lesion with no significant spinal cord changes in conventional MRI ,more decrease in FA, the more cord affection by disc lesion. This is agreed with paper showed MRI has limited role in the evaluation of spinal cord involvement. In chronic degenerative myelopathy caused by disk herniation or degenerative spinal canal stenosis, significant decrease of FA and increase of $\mathrm{ADC}$ has been found, including cases with no visible changes in the spinal cord on plain MRI (figure 4,5) ${ }^{[10,18]}$.

In recently published reports concerning contribution of DTI in cervical myelopathy, the authors have claimed that DTI proved to be more sensitive than conventional T2weighted images in assessment of cervical degenerative myelopathy ${ }^{[10,19,20 \& 21]}$. The decrease in the FA values may reflect the degree of microstructural disorganization of the spinal cord, suggesting either local extracellular edema or a smaller number of fibers matching a larger extracellular space, or both. On the other hand, minor lesions and edema with roughly preserved fibrillary microstructure of the spinal cord are not associated with major FA changes, as opposed to demyelination, cavitations and necrotic changes. Thus, the high FA values suggest that the microstructure of the spinal cord is preserved, even in cases with increased signal intensity of the spinal cord on T2-weighted images ${ }^{[19]}$.

Our study showed decrease in FA value with variable ADC according to type of lesion, this is matching with study showed a significant decrease of FA and variable ADC values has been found in extra-medullary tumors compressing the spinal cord (fig. 6). FA measurements proved to have high sensitivity and specificity in the detection of spinal cord pathology in patients with extramedullary spinal canal tumors ${ }^{[22]}$. 


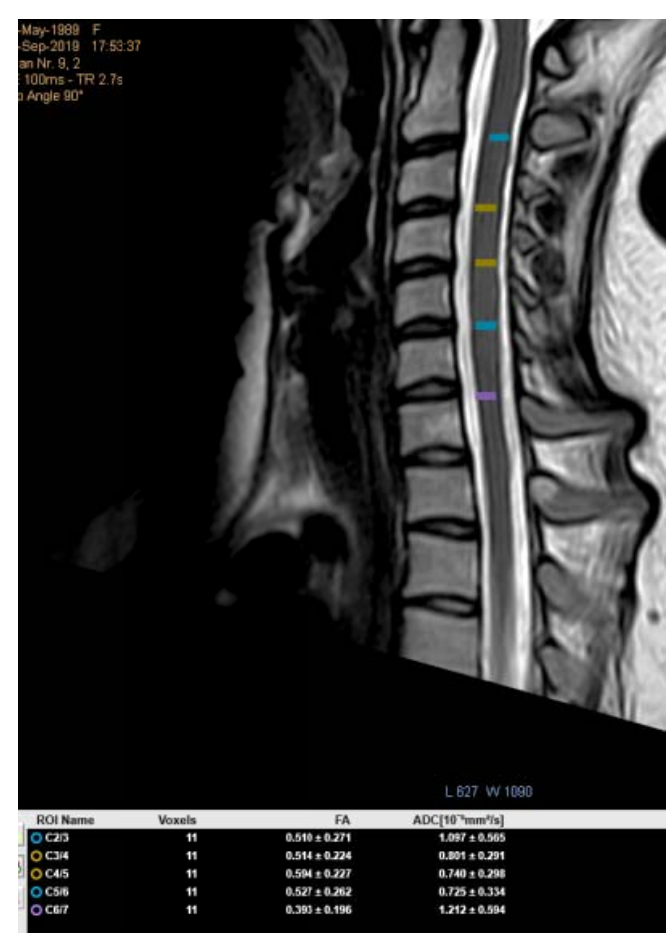

Fig. 3 Case 2: 32 year old female patient presented with rapidly progressing numbness in both arm associated with unilateral loss of vision, recently clinically proved to be MS.

Sagittal STIR with demyelinating plaque opposite C5 and bright T2 signal, DTI tables ROI reading shows low FA and high ADC value at C5level.

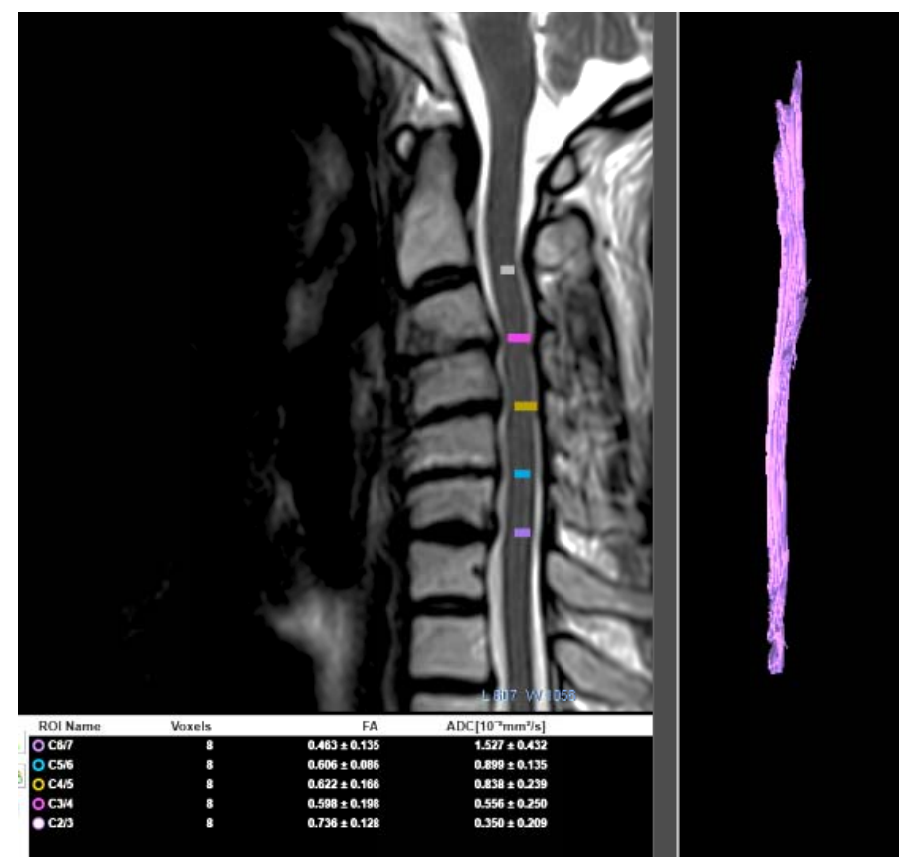

Fig. 2 Case 1: 35 year old female patient known case of MS complaining of recent neurological symptoms of both upper limb.

Sagittal T2 with demyelinating plaque opposite C6/7 presented with bright T2 signal and DTI tables ROI reading shows low $\mathrm{FA}$ and high $\mathrm{ADC}$ value at $\mathrm{C6} / 7$ level.

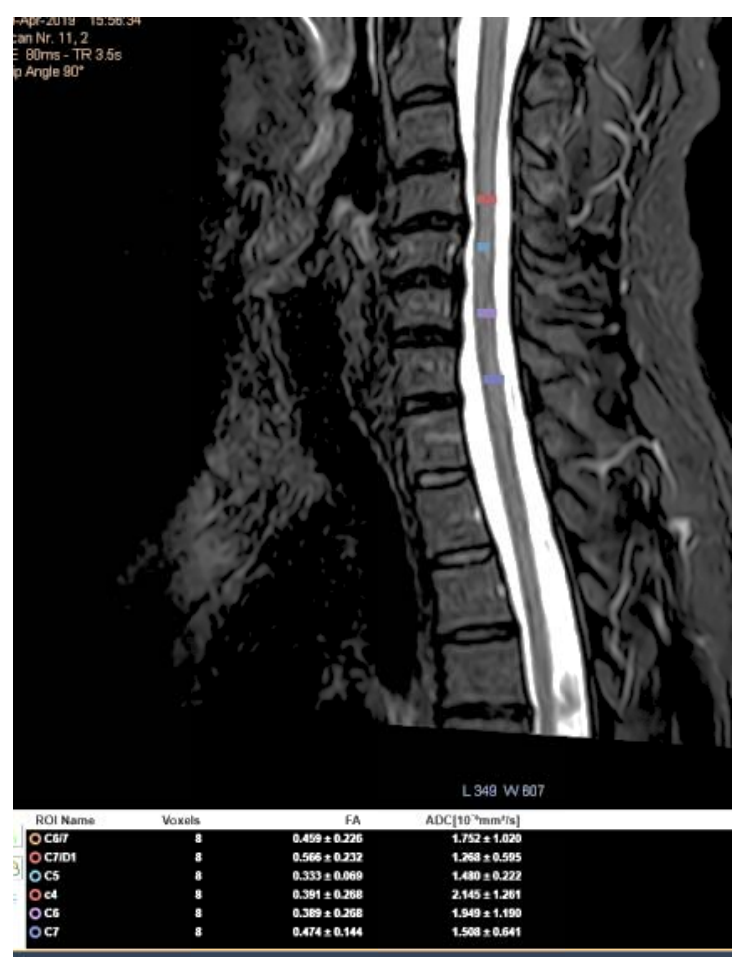

Fig. 4 case 3:55 year old female patient with cervical disc lesions mainly at (A) sagittal T2 with FA and ADC ROI readings. $\mathrm{C} 6 / 7$ level showed low $\mathrm{FA}$ value and high $\mathrm{ADC}$ value. (B) post processing tractography shows intact spinal cord fiber integrity. 


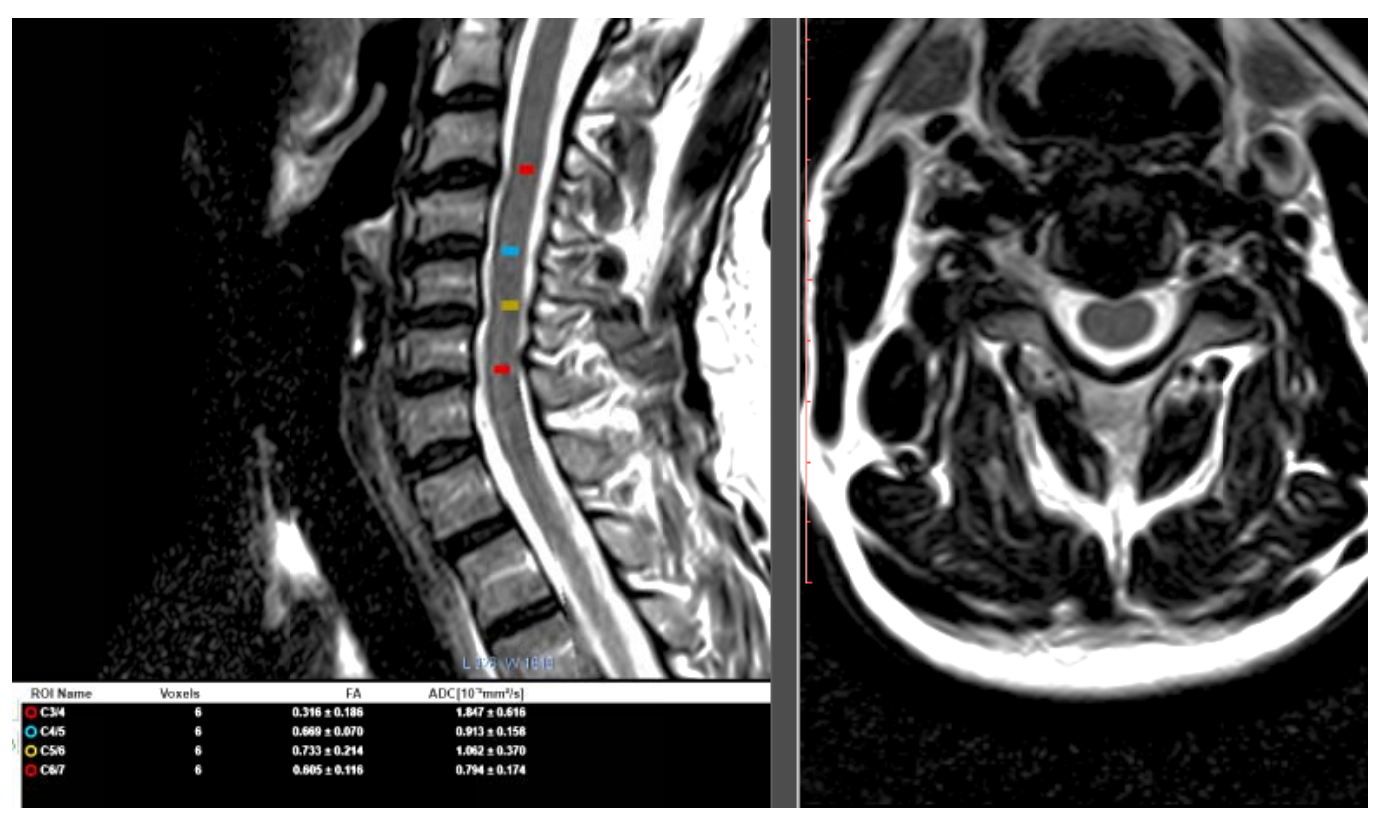

Fig. 5 case 4: 46 year old male patient with cervical disc lesions.

(A) sagittal T2WI with FA and ADC ROI readings shows C3/4 low FA value and high ADC value (B) axial T2WI at the level of $\mathrm{C} 3-\mathrm{C} 4$ central disc bulge with effacing anterior CSF space and abutting cervical spinal cord.

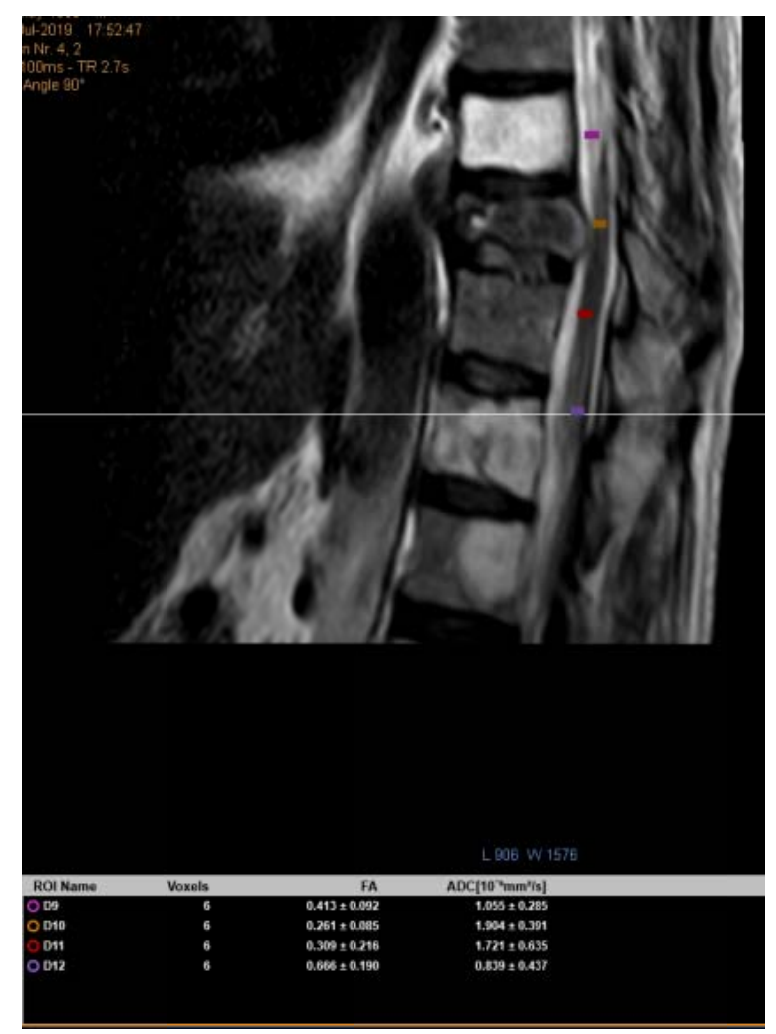

Fig. 6 Case 5: 61 year old male patient known case of cancer colon complaining of recent neurological symptoms of both lower limbs and back pain.

Sagittal T2 with reduced height of D10 with rounded posterior margin indenting the spinal cord and DTI tables ROI reading shows low FA and high ADC value at D10 level. 


\section{Conclusion:}

The study showed that the value of the newly additional sequence (DTI, DTT) with its dual measurable values ADC, FA helps in confirming early functional early affection of the spinal cord even before apparent change of cord signal, which has great impact of early diagnosis and prognosis.

\section{List of abbreviations:}

ADC: apparent diffusion coefficient.

DTI:diffusion tensor imaging

FA: fractional anisotropy.

MRI: Magnetic resonance imaging.

MS: multiple sclerosis.

DTT: diffusion tensor tractography.

ROI: region area of interest.

\section{REFERENCES:}

1. Seidenwurm D.J.: Myelopathy Am J Neuroradiol, 29 (2008), pp. 1032-1034

2. Chuan Z., Sushant K.D., DongJ.Y., and HanF. Y.,: Application of magnetic resonance imaging in cervical spondylotic myelopathy, World J Radiol. 2014 Oct 28; 6(10): 826-832. Published online 2014 Oct 28. doi: $10.4329 /$ wjr.v6.i10.826.

3. Jones DK: Diffusion MRI: Theory, Methods, and Applications. Oxford University Press: Oxford; 2010.

4. David F. et al.,: MR Diffusion Tensor Imaging and Fiber Tracking in Spinal Cord Compression American Journal of Neuroradiology June 2005, 26 (6) 1587-1594

5. Suri A, et al.,: Effect of intramedullary signal changes on the surgical outcome of patients with cervical spondylotic myelopathy. Spine J. 2003;3:33-45

6. Le Bihan D, Mangin JF et al.: Diffusion tensor imaging: Concepts and applications. J MagnReson Imaging 2001; 13:534-46. .

7. Marek J. S., Paweł S., and Joanna B.: Application of diffusion tensor imaging (DTI) in pathological changes of the spinalcord, Medical Science Monitor journal . 2012; 18(6): RA73-RA79.
8. Kazuki Ch., Shunka N., Tsukasa K.,et al.: Normal Values of Diffusion Tensor Magnetic Resonance Imaging Parameters in the Cervical Spinal Cord, Asian Spine Journal . 2015 Aug; 9(4): 541-547..

9. CartesF. Z., Ingorokva S., Kostron H., et.al.,: The value of diffusion tensor imaging (DTI) and tractography in patients with intraspinaltumours: a preliminary study ECR 2013, C-0877.

10. Lee JW, Kim JH, Park JB, et al.: Diffusion tensor imaging and fiber tractography in cervical compressive myelopathy: preliminary results. Skeletal Radiol. 2011; 40 (12): 1543-51

11. Wang $Y$, Sun $P$, Wang $Q$, et al.: Differentiation and quantification of inflammation, demyelination and axon injury or loss in multiple sclerosis. Brain $2015 ; 138: 1223-38$

12. Lin F, Yu C, Jiang T, et al.: Discriminative analysis of relapsing neuromyelitis optica and relapsing-remitting multiple sclerosis based on two-dimensional histogram from diffusion tensor imaging. Neuroimage2006; 31: 543-49.

13. Yu CS, Lin FC, Li KC, et al.: Diffusion tensor imaging in the assessment of normalappearing brain tissue damage in relapsing neuromyelitis optica. AJNR Am J Neuroradiol 2006; 27:1009-15.

14. Miraldi F, Lopes FC, Costa JV, Alves-Leon SV, Gasparetto EL.: Diffusion tensor magnetic resonance imaging may show abnormalities in the normal-appearing cervical spinal cord from patients with multiple sclerosis. Arq Neuropsiquiatr 2013; 71: 580-83.

15. Tallantyre EC, Bo L, Al-Rawashdeh O, et al.: Clinico-pathological evidence that axonal loss underlies disability in progressive multiple sclerosis. Mult Scler 2010; 16: 406-411.

16. Freund $\mathrm{P}$, Wheeler-Kingshott $\mathrm{C}$, Jackson $\mathrm{J}$, Miller D, Thompson A, Ciccarelli O.: Recovery after spinal cord relapse in multiple sclerosis is predicted by radial diffusivity. Mult Scler 2010; 16:1193-1202. 
17. Sasiadek M.J., Bladowska J.: Imaging of degenerative spine disease-the state of the art. Adv. Clin. Exp. Med. 2012;21:133-142.

18. Demir A, Ries M, Moonen CT et al: Diffusion-weighted MR imaging with apparent diffusion coefficient and apparent diffusion tensor maps in cervical spondylotic myelopathy. Radiology, 2003; 229(1): 37-43

19. Budzik JF, Balbi V, Le Thuc V et al: Diffusion tensor imaging and fibre tracking in cervical spondylotic myelopathy. Eur Radiol, 2011; 21: 426-33
20. Kara B, Celik A, Karadereler S et al: The role of DTI in early detection of cervical spondylotic myelopathy: a preliminary study with 3-T MRI. Neuroradiology, 2011; 53: 609-16.

21. Song T, Chen WJ, Yang B et al: Diffusion tensor imaging in the cervical spinal cord. Eur Spine J, 2011; 20: 422-28

22. Facon D, Ozanne A, Fillard P, et al. MR diffusion tensor imaging and fiber tracking in spinal cord compression. AJNR Am J Neuroradiol. 2005; 26(6):1587-94

\section{دور التصوير بالرنين المغناطيسى الأنثشاري للألياف العصبيه في تقييم أمراض الحبل الثوكي هند جلال الدين حسن محمد و رانيا علي معروف و محمد عمرو فاروق أبو العلا و نور هان رمزي محمدي}

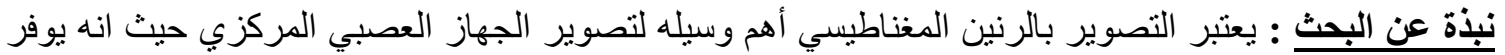

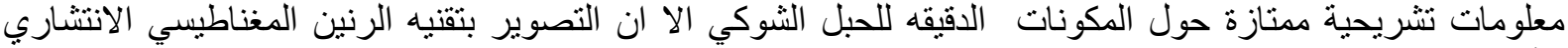

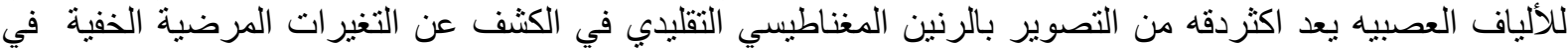
الحبل الشوكي. الهـف من البحث: دقة وفائده استخدام التصوير بتقنيه الرنين المغناطيسي الانتشاري للألياف العصبيه للنخاع الثوكي

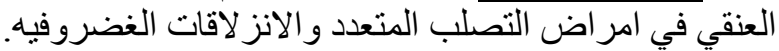

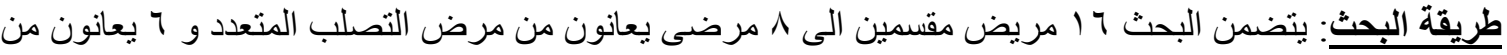

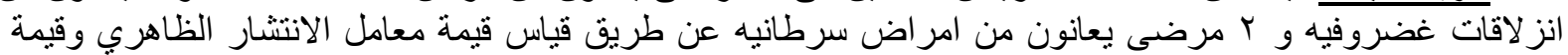

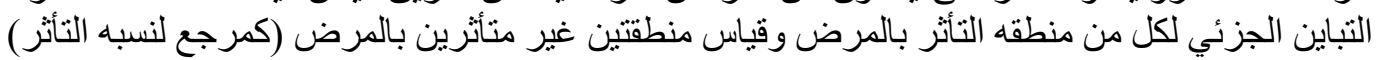
النتائج: يوجد فرق ذو قيمه كبير في قيمه التباين الجزئي وفرق ملحوظ في قيمه معامل الانتشارالظاهري بين المرض و المنطقه السليمه.

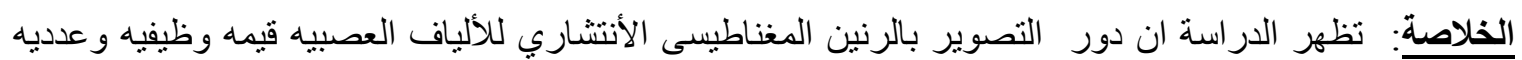

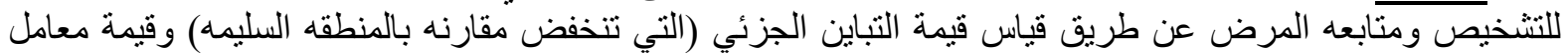
الانتشار الظاهري (تز اداد في المنطقه المصابه مقارمه بالمنطقه السليمه).
} 